\title{
Out-of-Pocket Costs for Patients Diagnosed with Tuberculosis in Different Healthcare Settings in Bandung, Indonesia
}

\author{
Susan M. McAllister, ${ }^{1 *}$ Bony Wiem Lestari, ${ }^{2,3,4}$ Trudy Sullivan, ${ }^{5}$ Panji Fortuna Hadisoemarto,, 3 Nur Afifah, ${ }^{3}$ Rosye Arosdiani Apip, ${ }^{6}$ \\ Megan Murray, ${ }^{7}$ Philip C. Hill, ${ }^{1}$ and Bachti Alisjahbana ${ }^{3,8}$ \\ ${ }^{1}$ Center for International Health, University of Otago, Dunedin, New Zealand; ${ }^{2}$ Department of Public Health, Faculty of Medicine, Universitas \\ Padjadjaran, Bandung, Indonesia; ${ }^{3}$ Tuberculosis Working Group, Infectious Disease Research Center, Faculty of Medicine, Universitas \\ Padjadjaran, Bandung, Indonesia; ${ }^{4}$ Department of Internal Medicine, Radboud Institute for Health Sciences, Radboud University Medical Center, \\ Nijmegen, The Netherlands; ${ }^{5}$ Department of Preventive and Social Medicine, University of Otago, Dunedin, New Zealand; ${ }^{6}$ Division of Disease \\ Control and Prevention, Bandung Municipal Health Office, Bandung, Indonesia; ${ }^{7}$ Department of Global Health and Social Medicine, Harvard \\ Medical School, Boston, Massachusetts; ${ }^{8}$ Department of Internal Medicine, Faculty of Medicine, Hasan Sadikin General Hospital, Universitas \\ Padjadjaran, Bandung, Indonesia
}

\begin{abstract}
Costs related to tuberculosis (TB) can impose a significant burden on patients and their families and create barriers to diagnosis and treatment. Our study aimed to quantify out-of-pocket costs expended by TB patients in Bandung, Indonesia. This cross-sectional study recruited adults with TB from community health centers (CHCs), public and private hospitals, and private practitioners (PPs). An interview was completed at the time of diagnosis or at their return for 2- or 6-month treatment. Costs were converted to U.S. dollars (US\$)-presented as median and interquartile range (IQR). Of 469 TB patients recruited, the mean age was 38 years and $57 \%$ were male. The median pretreatment direct cost per person was $\$ 37.51$ (IQR 20.79-71.24). Hospitalization, diagnostic tests, and travel costs were predominant. Higher pretreatment costs were associated with no health insurance ( $\$ 41.88$ versus $\$ 27.41, P<0.001)$, $\geq 6$ visits to a healthcare provider $(\$ 39.91$ versus $\$ 24.32, P<0.001)$, $\geq 60$ days pretreatment $(\$ 36.35$ versus $\$ 26.25, P=0.02)$, and presenting first to a PP $(\$ 40.71)$ or informal provider $(\$ 32.72)$ compared with private hospital $(\$ 21.26)$, public hospital $(\$ 19.63)$, or $\mathrm{CHC}$ (\$13.52) $(P=0.01)$. For a subsample of 106 patients with total pre- and posttreatment costs available, the median total cost was $\$ 243.66$ (IQR 128.46-550.71). For $26.5 \%$ of these patients, total costs were $\geq 20 \%$ of their annual household income. Despite having a good network of free TB diagnostic and treatment services throughout Bandung, patients experienced significant out-of-pocket costs. Increased uptake of the National Health Insurance, and systems for early recognition and diagnosis of TB, will contribute toward reducing costs.
\end{abstract}

\section{INTRODUCTION}

The connection between tuberculosis (TB) and poverty is well established. ${ }^{1}$ Patients with TB also encounter numerous barriers to seeking diagnosis and treatment-all of which are more pronounced for lower socioeconomic groups. ${ }^{2}$ One such barrier is the cost incurred by patients and their families. A systematic review from 40 surveys in low- and middleincome countries reported a median cost of US $\$ 397$, and from the eight studies that separated costs according to when they occurred, half the costs were before TB treatment. ${ }^{3}$ Both direct costs, such as paying for medication, transport, and accommodation, and indirect costs, such as loss of income, can constitute a significant proportion of household income, triggering a spiral into deeper poverty. ${ }^{3,4}$ This problem was recognized by the WHO in their End TB Strategy, which included a target of no TB-affected family facing catastrophic costs because of TB by the year $2020 .^{5}$

Indonesia is a high TB burden country with a TB incidence rate of 316 (288-345) per 100,000 population in 2018. ${ }^{6}$ Much of the diagnosis and treatment of TB is carried out in community health centers (CHCs) and public hospitals. Diagnosis by sputum microscopy and provision of anti-TB medication in these health facilities are provided free of charge by the $\mathrm{Na}$ tional TB Programme (NTP), but extra diagnostic services, such as chest X-ray, have to be paid for by the patient. People with TB symptoms can also present to a private practitioner (PP) or hospital ${ }^{7-9}$ where patients themselves incur most of the

*Address correspondence to Susan M. McAllister, Centre for International Health, University of Otago, P.O. Box 56, Dunedin 9054, New Zealand. E-mail: sue.mcallister@otago.ac.nz costs. In 2014, Indonesia implemented a National Health Insurance scheme, known as the Jaminan Kesehatan Nasional. ${ }^{10,11}$ Approximately $74 \%$ of Indonesia's population are under the scheme. ${ }^{12}$ The aim of the scheme is to provide health coverage for all, with the government paying the modest premiums of the poor. Under this scheme, Indonesian citizens are entitled to equal access to health care, with the aim of improving health outcomes and keeping healthcare costs down through strengthening primary care and improving procurement, distribution, and utilization of key medicines. However, it is thought that out-of-pocket costs incurred by patients in Indonesia remain high, although very little is actually known. Our study, therefore, aimed to describe the direct costs to patients before a TB diagnosis and to identify factors contributing to higher costs. Secondary to this, we aimed to describe costs, coping mechanisms, and catastrophic costs on a subsample of patients recruited at the end of their 6month treatment course.

\section{METHODS}

Study setting, participant selection, and eligibility criteria. The study was undertaken in Bandung, a city of approximately 2.5 million people in West Java, Indonesia. This study was also part of the INSTEP study (investigation of services delivered for TB by external care system-especially the private sector) examining the role of PPs in caring for TB patients. The primary health needs of Bandung inhabitants are served by $73 \mathrm{CHCs}$ located throughout the city, from which we randomly selected $30 \mathrm{CHC}$ areas according to the size of the population. From these areas, $10 \mathrm{CHCs}$ were randomly selected, and two (of seven) public and three (of 10) private 
hospitals were purposively selected according to the number of TB patients detected in these hospitals, as well as the hospital management being willing to collaborate. Patients were then recruited consecutively from each of these sites. Recruitment of patients seen by PPs was carried out by first mapping the registered PPs in the selected $\mathrm{CHC}$ areas, then identifying PPs who had diagnosed at least one TB patient in the previous 6 months $(n=282$ ) and were willing to participate ( $n=145$ ), after which patients diagnosed with TB by these PPs were consecutively recruited.

Eligible participants were older than 18 years, newly diagnosed pulmonary TB patients, and recruited at the time of diagnosis or at the time of return for their 2- or 6-month treatment review. Patients presenting for re-treatment of TB were excluded. Recruitment was undertaken from October 2017 to January 2019. Tuberculosis nurses in the CHCs, TB clinic physicians in the hospitals, and PPs were informed of the study and asked to seek initial consent from potential patients. The list of patients was obtained on a weekly basis by the research nurse, who then contacted the patient to arrange a time and place for an in-person interview. The study was approved by the University of Otago Human Ethics Committee, Dunedin, New Zealand (No. H17/003), and the Health Research Ethics Committee, Faculty of Medicine, Universitas Padjadjaran (No. 687/UN6.C.10/PN/2017).

Interview and data collected. Following informed consent, an interview was undertaken to obtain demographic (age, gender, education, and ethnicity), clinical (diagnosis date, treatment, and TB history), and cost information. We used a questionnaire, adapted to the Indonesian context, from the WHO's "Tool to estimate patient costs" cludes patient and health system delays, direct and indirect costs, coping costs, and socioeconomic information. All interviews and study documentation were in the Bahasa Indonesian language. Questionnaires were piloted with 20 TB patients before finalizing the questionnaire. At completion of the interview, patients were given a cash amount equivalent to approximately US\$4 in appreciation of their participation. Research nurses were trained and provided with standard operating procedures to ensure consistency in interviewing.

Sample size. Based on the 2015 Bandung Municipal Health Office report, a total of 2087 positive TB patients were notified by the $73 \mathrm{CHCs}$ (average of 28 patients per $\mathrm{CHC}$ per year), and a further 3,560 from directly observed treatment, short-course hospitals and lung clinics. Based on these numbers, we estimated that $37 \%$ of TB patients were registered in $\mathrm{CHCs}$ and $63 \%$ in hospitals. There was limited information about the number and proportion of TB patients who visit PPs, but we assumed this to be at least $30 \%$. Our sample of TB patients was, therefore, recruited from $\mathrm{CHCs}(30 \%)$, hospitals (40\%), and PPs (30\%). Considering a 10\% nonresponse rate, a total sample size of approximately 400 was estimated (120 from CHCs, 160 from hospitals, and 120 from PPs).

Definitions. We defined direct costs as costs for the patient and their family or accompanying person linked to seeking diagnosis and treatment for TB, including medical expenses, administration fees, transport, additional food requirements, and accommodation expenditure. ${ }^{13}$ Hospitalization costs included all costs related to a patient's stay in hospital, such as drugs, diagnostic tests, administration fees, travel, and food as well as costs for any family member or friend to accompany them. We separated direct costs into those that occurred up to and including the time of diagnosis (pretreatment).

For the subsample of patients recruited at the time of their 6-month treatment review, we collected information on direct costs occurring after diagnosis (post-diagnosis), indirect costs, total costs, coping mechanisms, and catastrophic costs. We defined indirect costs as personal income loss due to TB illness for those who were income earners-estimated as the monthly personal take-home pay before the TB illness by the number of months not working because of TB, net of any reimbursement from insurance. ${ }^{14}$ Total costs included all reported direct and indirect costs. We defined coping mechanisms as measures taken to meet daily requirements of the household that included the sale of assets or borrowing money as a consequence of having TB. ${ }^{13}$ Catastrophic costs were defined as total costs (direct and indirect) that exceeded $20 \%$ of the household's annual income. ${ }^{14}$ A sensitivity analysis using a $10 \%$ and a $25 \%$ threshold for catastrophic costs was also estimated. ${ }^{15}$ Households were classified into poor or nonpoor using a threshold of US\$1.90 per capita per day (calculated as total household income per month before the onset of TB symptoms divided by the number of people in the household, divided by 30 days). ${ }^{16,17}$

Statistical analysis. Information collected during interviews was recorded on a paper questionnaire and later entered into a REDCap database ${ }^{18}$ and cross-checked by two researchers. Costs and income information were collected in Indonesian rupiah and converted to U.S. dollar (USD) according to the midway World Bank official exchange rate period average of 2017 and 2018 (13,755 Indonesian Rupiah to 1 USD). ${ }^{19}$ The analysis was conducted in two parts:

1. Full sample of patients recruited at the time of diagnosis, or 2-month or 6-month review.

A chi-square test was used to compare groups according to the recruitment site, with respect to non-missing data. Pretreatment direct costs were estimated and presented as medians and interquartile range (IQR). To determine characteristics associated with higher pretreatment direct costs, quantile regression analysis was used to compare medians. Any variable that reached a $P$-value of less than 0.20 was included in a multivariable quantile regression analysis that included site of recruitment as an independent variable.

2. Subsample of patients recruited at the time of their 6month review.

Post-diagnosis direct costs, income loss, and total costs were estimated and presented as medians and IQR. Coping mechanisms are reported as a proportion, and for those who borrowed money, the amount is presented as medians and IQR. The proportion and 95\% Cls were estimated for catastrophic costs at the $10 \%, 20 \%$, and $25 \%$ threshold levels. Statistical analyses were undertaken using Stata Statistical Software 12.1 (StataCorp, College Station, TX). ${ }^{20}$

\section{RESULTS}

Full sample. Study participants. From a total of 515 eligible patients, $30(6 \%)$ refused to participate and $16(3 \%)$ were unable to be interviewed, leaving 469 patients who completed an interview (CHCs, $n=138$ [29\%]; public hospitals, $n=106$ [23\%]; private hospitals, $n=104$ [22\%]; PPs, $n=121$ [26\%]). Of 
these 469 patients, $252(53.7 \%)$ were recruited at the time of their diagnosis, 111 (23.7\%) when returning for their 2-month treatment review, and 106 (22.6\%) when returning for their final 6-month treatment review. The mean age of patients was 38 years, and just over half $(56.5 \%)$ were males. Almost twothirds ( $n=284 ; 60.6 \%$ ) of patients reported their normal work status as full- or part-time, and $43.9 \%$ of patients were the main income earner in the household. A higher proportion of patients recruited in the public and private hospitals reported having national health insurance compared with those recruited through $\mathrm{CHCs}$ and $\mathrm{PPs}(79.2 \%, 90.4 \%, 53.6 \%$, and $61.2 \%$, respectively; $P<0.001$ ) (Table 1). A higher proportion of patients recruited in $\mathrm{CHCs}$ were classified as householdincome poor than those recruited through public or private hospitals or PPs $(43.5 \%, 28.3 \%, 33.7 \%$, and $26.5 \%$, respectively; $P=0.019$ ) (Table 1$)$. A total of 140 (29.9\%) patients reported having a comorbidity which included conditions such as diabetes $(n=38)$, hypertension $(n=31)$, gastritis ( $n=45)$, high cholesterol $(n=11)$, heart disease $(n=8)$, and asthma $(n=12)$.

Time and visits to healthcare provider pretreatment. The median number of visits to any healthcare provider up to and including the time of diagnosis was 6.0 (IQR 4-8). When the number of visits was dichotomized ( $<6$ visits; $\geq 6$ visits), a greater proportion of patients recruited in $\mathrm{CHCs}(66.7 \%)$ reported $\geq 6$ visits than those recruited in public $(52.8 \%)$ and private $(34.6 \%)$ hospitals, and PPs $(53.7 \%)(P<0.001)$ (Table 1). The median time from the onset of first symptoms to diagnosis was 63 (IQR 35-113) days. When the number of days was dichotomized, there was a higher proportion of $\mathrm{CHC}$

TABLE 1

Characteristics of participants ( $n=469)$, according to the recruitment site

\begin{tabular}{|c|c|c|c|c|c|}
\hline Characteristic & Community health center $n=138$ & Public hospital $n=106$ & Private hospital $n=104$ & Private practice $n=121$ & $P$-value \\
\hline \multicolumn{6}{|l|}{ Gender } \\
\hline Male & $80(58.0)$ & $45(42.5)$ & $43(41.4)$ & $63(52.1)$ & \multirow[t]{3}{*}{0.721} \\
\hline Female & $58(42.0)$ & 61 (57.5) & $61(58.6)$ & $58(47.9)$ & \\
\hline Age (years), mean (SD) & $38.6 \pm 14.2$ & $35.9 \pm 14.6$ & $39.9 \pm 15.9$ & $37.4 \pm 15.4$ & \\
\hline \multicolumn{6}{|l|}{ Age-group (years), $n(\%)$} \\
\hline $18-29$ & $42(30.4)$ & $48(45.3)$ & $40(38.5)$ & $52(43.0)$ & \multirow[t]{4}{*}{0.012} \\
\hline 30-39 & 45 (32.6) & $22(20.8)$ & $13(12.5)$ & $21(17.4)$ & \\
\hline $40-49$ & $22(15.9)$ & $14(13.2)$ & 19 (18.3) & $21(17.4)$ & \\
\hline $50+$ & $29(20.1)$ & $22(20.7)$ & 32 (30.8) & 27 (22.3) & \\
\hline \multicolumn{6}{|l|}{ Marital status, $n(\%)$} \\
\hline Single & $40(29.0)$ & $41(38.7)$ & $32(30.8)$ & $42(34.7)$ & \multirow[t]{3}{*}{0.356} \\
\hline Married & $87(63.0)$ & $57(53.8)$ & $66(63.5)$ & $63(52.1)$ & \\
\hline Widowed/divorced & $11(8.0)$ & $8(7.5)$ & $6(5.7)$ & $16(13.2)$ & \\
\hline \multicolumn{6}{|l|}{ Comorbidity, $n(\%)$} \\
\hline Yes & $31(22.5)$ & $24(22.6)$ & $47(45.2)$ & $38(31.4)$ & \multirow[t]{2}{*}{$<0.001$} \\
\hline No & $107(77.5)$ & $82(77.4)$ & $57(54.8)$ & $83(68.6)$ & \\
\hline \multicolumn{6}{|l|}{ Education, $n(\%)$} \\
\hline $\begin{array}{l}\text { No formal schooling/primary } \\
\text { completed }\end{array}$ & $32(23.2)$ & $20(18.9)$ & $23(22.1)$ & $29(24.0)$ & \multirow[t]{4}{*}{0.289} \\
\hline Secondary completed & $27(19.6)$ & $12(11.3)$ & $22(21.2)$ & $17(14.1)$ & \\
\hline High school completed & $66(47.8)$ & $61(57.5)$ & $50(48.1)$ & $55(45.5)$ & \\
\hline College/university/postgraduate & $13(9.4)$ & 13 (12.3) & $9(8.6)$ & $20(16.5)$ & \\
\hline \multicolumn{6}{|l|}{ Employment status, $n(\%)$} \\
\hline Full- or part-time work & $87(63.0)$ & $64(60.4)$ & $58(55.8)$ & $75(62.0)$ & \multirow[t]{4}{*}{0.121} \\
\hline Student (school/university) & $5(3.6)$ & 12 (11.3) & $2(1.9)$ & $9(7.4)$ & \\
\hline Housewife/husband/retired & $32(23.2)$ & $17(16.0)$ & $29(27.9)$ & $20(16.5)$ & \\
\hline Unemployed/looking for work & $14(10.1)$ & $13(12.3)$ & $15(14.4)$ & $17(14.1)$ & \\
\hline \multicolumn{6}{|l|}{ Insurance, $n(\%)$} \\
\hline No insurance & $64(46.4)$ & $22(20.8)$ & $10(9.6)$ & $47(38.8)$ & \multirow[t]{2}{*}{$<0.001$} \\
\hline National health insurance/private & $74(53.6)$ & $84(79.2)$ & $94(90.4)$ & $74(61.2)$ & \\
\hline \multicolumn{6}{|c|}{ Number of people in the household, $n(\%)$} \\
\hline$\leq 4$ & $82(59.4)$ & $69(65.1)$ & $58(55.8)$ & $70(58.8)$ & \multirow[t]{2}{*}{0.549} \\
\hline$>4$ & $56(40.6)$ & $37(34.9)$ & $46(44.2)$ & $51(42.2)$ & \\
\hline \multicolumn{6}{|l|}{ Income-earning job, $n(\%)$} \\
\hline Yes & $87(63.0)$ & $64(60.4)$ & $58(55.8)$ & $75(62.0)$ & \multirow[t]{2}{*}{0.692} \\
\hline No & $51(37.0)$ & $42(39.6)$ & $46(44.2)$ & $46(38.0)$ & \\
\hline \multicolumn{6}{|c|}{ Household primary income earner, $n(\%)$} \\
\hline Patient & 68 (49.3) & $43(40.6)$ & $39(37.5)$ & $56(46.3)$ & \multirow[t]{2}{*}{0.250} \\
\hline Not patient & $70(50.7)$ & $63(59.4)$ & $65(62.5)$ & $65(53.7)$ & \\
\hline \multicolumn{6}{|l|}{ Household income, $n(\%)$} \\
\hline Poor & $60(43.5)$ & $30(28.3)$ & $35(33.7)$ & $32(26.5)$ & \multirow[t]{3}{*}{0.019} \\
\hline Not poor & $54(39.1)$ & $51(48.1)$ & $38(36.5)$ & $63(52.1)$ & \\
\hline Household income not available & $24(17.4)$ & $25(23.6)$ & $31(29.8)$ & $26(21.5)$ & \\
\hline Number of visits to the healthcare pr & Defore diagnosis, $n$ (\%) & & & & \\
\hline$<6$ & $46(33.3)$ & $50(47.2)$ & $68(65.4)$ & $56(46.3)$ & $<0.001$ \\
\hline$\geq 6$ & $92(66.7)$ & $56(52.8)$ & $36(34.6)$ & $65(53.7)$ & \\
\hline Days from the first symptoms to diag & $n(\%)$ & & & & \\
\hline$<60$ & $53(39.0)$ & $45(43.3)$ & $62(63.3)$ & $57(48.3)$ & 0.002 \\
\hline$\geq 60$ & 83 (61.0) & $59(56.7)$ & $36(36.7)$ & $61(51.7)$ & \\
\hline
\end{tabular}

${ }^{\star}$ Thirteen people did not present with symptoms and were, therefore, excluded from this variable. 
patients who had 60 or more days between first symptoms and diagnosis, versus less than 60 days, than public hospital, private hospital, and PP patients $(61.0 \%, 56.7 \%, 36.7 \%$, and $51.7 \%$, respectively; $P=0.002$ ) (Table 1 ).

Pretreatment direct costs. The median pretreatment direct cost per person (excluding hospitalization costs) for the 469 patients was $\$ 32.50$ (IQR 15.85-55.11). The median was highest in patients who were recruited at the time of their diagnosis (\$36.02) compared with 2 months (\$26.90) and 6 months (\$29.04) $(P=0.008)$. The median pretreatment direct cost per person (including hospitalization costs) was \$37.51 (IQR 20.79-71.25). Ninety-seven patients said they had been hospitalized as a consequence of their TB at some stage in the time leading up to or around their TB diagnosis, resulting in expenses relating to hospitalization being the highest cost item (median \$58.16, IQR 36.35-109.05). These patients were mostly recruited in the public $(n=44)$ and private hospitals $(n=34)$ (Table 2$)$.

After hospitalization costs, the highest direct cost for patients in most recruitment sites was for diagnostic tests (i.e., sputum tests and chest X-ray) and medication not directly related to TB; however, for patients recruited in public hospitals, the highest median cost was for travel. The median cost per person for sputum tests ranged from $\$ 5.45$ in public hospitals to $\$ 13.10$ in private hospitals. For a chest $X$-ray, the median cost ranged from $\$ 6.54$ in public hospitals to $\$ 11.27$ in private hospitals, and for medication, the median cost ranged from $\$ 8.00$ in $\mathrm{CHCs}$ to $\$ 11.01$ in PPs. The median pretreatment direct cost was the highest in patients recruited through PPs (\$41.44, IQR 25.66-64.34) compared with public hospitals (\$34.82, IQR 20.72-64.78), CHCs (\$30.13, IQR 14.50-40.86), and private hospitals (\$17.90, IQR 6.58-55.47) (Table 2).

Factors associated with higher pretreatment direct costs. Factors significantly associated with higher pretreatment direct costs (excluding hospitalization) were not having national health insurance (\$41.88 versus $\$ 27.41$; adjusted coefficient $10.40 ; P<0.001$ ), having more than six visits to a healthcare provider before diagnosis (\$39.91 versus $\$ 24.32$; adjusted coefficient 13.23; $P<0.001$ ), $\geq 60$ days before diagnosis (\$36.35 versus $\$ 26.25$; adjusted coefficient $6.47 ; P=0.021$ ), and the first healthcare provider being either a PP $(\$ 40.71)$ or informal provider (\$32.72) compared with a private hospital (\$21.26), public hospital (\$19.63), or CHC (\$13.52) (adjusted coefficient 2.71; $P=0.011$ ) (Table 3).

Subsample $(n=106)$ of patients recruited at the time of their 6-month treatment review. Direct costs. The median post-diagnosis direct cost per person was \$25.00 (IQR 9.81-51.98). This median was considerably higher in patients recruited through PPs $(\$ 55.25$, IQR 25.08-145.76) than public hospitals (\$39.58, IQR 13.74-67.28), private hospitals (\$26.79, IQR 14.83-47.11), and CHCs (\$11.63, IQR 7.20-16.21). Again, the highest cost item was for the 10 patients who had been hospitalized (median \$109.05, IQR 58.16-363.50). Another high cost item was travel (median \$11.63; IQR 6.11-27.63), which was highest for patients recruited through public hospitals (\$22.17, IQR 6.54-38.17) (Table 4).

Indirect costs (personal income loss). Sixty-one patients $(57.5 \%)$ were in an income-earning job before their TB illness; among them, four reported no personal income information. Of the remaining 57 people, $86 \%$ reported income loss. The median personal income loss for the entire time of their TB illness and treatment was \$152 (IQR 65.43-690.66) and ranged from $\$ 101.78$ (IQR 70.28-763.36) for patients recruited through PPs to $\$ 257.36$ (IQR 61.80-727.00) for patients recruited in public hospitals (Table 5 ).

Total cost per person. After combining direct costs before and after diagnosis and indirect costs, the median total cost per person was $\$ 243.66$ (IQR 128.46-550.71). This total cost ranged from $\$ 147$ (IQR 103.53-438.17) for the 31 patients recruited in CHCs to $\$ 334.89$ (IQR 179.79-550.93) for the 26 patients recruited in private hospitals (Table 5). A greater proportion of this total cost was for personal income loss (69\%).

Coping mechanisms. Almost a third $(n=33)$ of the patients reported they had borrowed money to cover costs of their TB illness, with a median amount borrowed ranging from \$36.35 (IQR 7.27-72.70) for CHC patients to \$145.40 (IQR 14.54-363.50) for private hospital and PP (IQR 72.70-218.10) patients (Table 5). Thirteen people (12.3\%) sold assets, mostly jewelry, to finance the cost of their TB illness.

Catastrophic costs. Of the 106 patients recruited at 6 months, household income information was available for 83 (78.3\%). The proportion of patients who incurred catastrophic costs at a $20 \%$ threshold of their annual household income was $26.5 \%$ (95\% Cl: 16.8-36.2). This proportion was 21.7 (95\% Cl: 12.6-30.7) when a 25\% threshold was used or $38.6 \%$ (95\% Cl: 27.9-49.2) when a 10\% threshold was used.

\section{DISCUSSION}

Despite a National TB Control Program providing predominantly free-of-charge diagnostic and treatment services

TABLE 2

Pretreatment direct costs USD per patient with tuberculosis $(n=469)$ according to the site of recruitment and main cost categories

\begin{tabular}{|c|c|c|c|c|c|c|c|c|}
\hline \multirow[b]{2}{*}{ Cost category } & \multicolumn{2}{|c|}{ Community health center, $n=138$} & \multicolumn{2}{|r|}{ Public hospital, $n=106$} & \multicolumn{2}{|r|}{ Private hospital, $n=104$} & \multicolumn{2}{|r|}{ Private practice, $n=121$} \\
\hline & $N$ & Median (IQR), USD & $N$ & Median (IQR), USD & $N$ & Median (IQR), USD & $N$ & Median (IQR), USD \\
\hline Administration & 120 & 4.87 (2.18-9.88) & 86 & $7.81(3.63-11.63)$ & 59 & 8.36 (2.18-16.72) & 107 & $7.27(2.91-14.54)$ \\
\hline Sputum tests & 50 & 7.27 (3.27-15.27) & 51 & $5.45(3.64-10.17)$ & 32 & $13.10(5.45-31.81)$ & 54 & 9.19 (3.63-15.05) \\
\hline Chest X-ray & 84 & $7.43(5.81-12.18)$ & 59 & $6.54(6.18-11.99)$ & 33 & 11.27 (8.32-13.23) & 96 & 9.34 (6.18-15.99) \\
\hline Medication* & 116 & $8.00(4.36-12.72)$ & 89 & 8.43 (3.63-20.72) & 71 & 10.17 (2.18-29.08) & 108 & 11.01 (5.09-21.30) \\
\hline Travel & 138 & $5.09(3.05-7.56)$ & 106 & 9.19 (5.37-15.63) & 102 & 4.36 (2.54-8.72) & 120 & 7.45 (3.70-10.90) \\
\hline Food & 61 & $1.81(0.73-2.91)$ & 86 & $2.90(1.16-5.09)$ & 71 & 2.91 (1.45-4.72) & 57 & $1.45(0.73-3.13)$ \\
\hline Subtotal cost per person & 138 & $30.13(14.50-40.86)$ & 106 & 34.82 (20.72-64.78) & 104 & $17.90(6.58-55.47)$ & 121 & $41.44(25.66-64.34)$ \\
\hline Hospitalization & 7 & 36.35 (21.81-79.97) & 44 & $58.16(36.35-123.59)$ & 34 & $61.80(36.35-163.58)$ & 12 & $69.79(21.81-72.70)$ \\
\hline $\begin{array}{l}\text { Total cost per person } \\
\quad \text { (including hospitalization) }\end{array}$ & 138 & $31.77(14.90-42.17)$ & 106 & 51.87 (28.72-113.05) & 104 & $37.29(8.30-100.62)^{\prime}$ & 121 & $44.71(26.68-68.12)$ \\
\hline
\end{tabular}

IQR = interquartile range; USD = U.S. dollar; $\$ 1=13,755$ Indonesian rupiah.

${ }^{*}$ Medication could include antibiotics or treatment accessed from pharmacies or informal providers. 
TABLE 3

Factors associated with median pretreatment direct costs (excluding hospitalization costs)

\begin{tabular}{|c|c|c|c|c|c|c|c|}
\hline \multirow[b]{2}{*}{ Characteristic } & \multirow[b]{2}{*}{ Median U.S. dollar } & \multicolumn{3}{|c|}{ Unadjusted } & \multicolumn{3}{|c|}{ Adjusted $^{*}$} \\
\hline & & Coefficient & $P$-value & $95 \% \mathrm{Cl}$ & Coefficient & $P$-value & $95 \% \mathrm{Cl}$ \\
\hline \multicolumn{8}{|l|}{ Gender } \\
\hline Male & 32.50 & - & - & - & - & - & - \\
\hline Female & 32.60 & -0.22 & 0.941 & $-6.03-5.59$ & - & - & - \\
\hline \multicolumn{8}{|l|}{ Age-group (years) } \\
\hline $18-39$ & 32.72 & - & - & - & - & - & - \\
\hline $40+$ & 32.42 & -0.22 & 0.945 & $-6.38-5.94$ & - & - & - \\
\hline \multicolumn{8}{|l|}{ Comorbidity } \\
\hline No & 32.35 & - & - & - & - & - & - \\
\hline Yes & 32.72 & 0.36 & 0.915 & $-6.32-7.05$ & - & - & - \\
\hline \multicolumn{8}{|l|}{ Education } \\
\hline$<$ Primary school completed & 33.15 & - & - & - & - & - & - \\
\hline$\geq$ Secondary school & 32.50 & -1.31 & 0.714 & $-8.33-5.71$ & - & - & - \\
\hline \multicolumn{8}{|l|}{ Insurance } \\
\hline No insurance & 41.88 & - & - & - & - & - & - \\
\hline National health/private insurance & 27.41 & -14.32 & $<0.001$ & $-20.5-8.13$ & -10.40 & $<0.001$ & $-16.2-4.61$ \\
\hline \multicolumn{8}{|l|}{ Household members } \\
\hline$\leq 4$ & 32.72 & - & - & - & - & - & - \\
\hline$>4$ & 32.17 & -0.36 & 0.903 & $-6.20-5.47$ & - & - & - \\
\hline \multicolumn{8}{|l|}{ Income-earning job } \\
\hline No & 32.35 & - & - & - & - & - & - \\
\hline Yes & 32.61 & 0.36 & 0.903 & $-5.48-6.21$ & - & - & - \\
\hline \multicolumn{8}{|l|}{ Primary income earner } \\
\hline Patient & 32.42 & - & - & - & - & - & - \\
\hline Not patient & 32.72 & -0.22 & 0.941 & $-6.02-5.58$ & - & - & - \\
\hline \multicolumn{8}{|c|}{ Number of visits to a healthcare provider pre-diagnosis } \\
\hline$<6$ & 24.32 & - & - & - & - & - & - \\
\hline$\geq 6$ & 39.91 & 14.83 & $<0.001$ & $8.51-21.15$ & 13.23 & $<0.001$ & $7.55-18.91$ \\
\hline \multicolumn{8}{|c|}{ Days from the first symptoms to diagnosis } \\
\hline$<60$ & 26.25 & - & - & - & - & - & - \\
\hline$\geq 60$ & 36.35 & 10.10 & 0.001 & $4.41-15.80$ & 6.47 & 0.021 & $0.97-11.96$ \\
\hline \multicolumn{8}{|l|}{ First healthcare provider visited } \\
\hline Community health center & 13.52 & - & - & - & - & - & - \\
\hline Public hospital & 19.63 & - & - & - & - & - & - \\
\hline Private hospital & 21.26 & - & - & - & - & - & - \\
\hline Private practitioner & 40.71 & - & - & - & - & - & - \\
\hline Informal provider & 32.72 & 4.65 & $<0.001$ & $2.52-6.79$ & 2.71 & 0.011 & $0.63-4.79$ \\
\hline
\end{tabular}

for TB, and a National Health Insurance scheme, patients in our study continued to use the private health sector and experience significant out-of-pocket costs. Pretreatment direct costs, after hospitalization, were mostly for diagnostic tests, non-TB medication, and travel. These costs were significantly more for patients who had no national health insurance, who had longer time or more visits to a healthcare provider before being diagnosed, or who first visited a private or informal healthcare provider when becoming unwell. For the subsample of patients for whom cost details were available before their diagnosis as well as during their 6-month treatment time, costs were considered as catastrophic for just over a quarter, with a greater proportion of these costs being attributable to income loss.

The main pretreatment expenditure was for costs relating to hospitalization, which was also identified as a key driver of

TABLE 4

Post-diagnosis direct costs USD per person for patients with tuberculosis who were recruited at 6 months $(n=106)$ according to the site of recruitment and main cost categories

\begin{tabular}{|c|c|c|c|c|c|c|c|c|}
\hline \multirow[b]{2}{*}{ Cost category } & \multicolumn{2}{|c|}{ Community health center, $n=31$} & \multicolumn{2}{|r|}{ Public hospital, $n=32$} & \multicolumn{2}{|r|}{ Private hospital, $n=26$} & \multicolumn{2}{|r|}{ Private practice, $n=17$} \\
\hline & $N$ & Median (IQR), USD & $N$ & Median (IQR), USD & $N$ & Median (IQR), USD & $N$ & Median (IQR), USD \\
\hline Administration & 20 & 2.62 (2.07-3.27) & 9 & $10.90(9.81-25.45)$ & 7 & 13.09 (9.45-21.81) & 10 & 24.54 (20.36-43.62) \\
\hline Sputum tests & 4 & 5.81 (3.63-8.00) & 4 & 8.36 (6.72-8.72) & 2 & 9.61 (8.00-11.23) & 2 & 20.36 (14.54-26.17) \\
\hline Chest X-ray & 2 & 19.88 (9.23-30.53) & 5 & 12.36 (6.18-12.36) & 3 & 8.36 (7.56-17.65) & 7 & 14.54 (10.47-26.17) \\
\hline Medication & 0 & - & 8 & 6.62 (1.96-12.57) & 9 & 21.81 (3.63-64.87) & 9 & 69.07 (40.35-109.05) \\
\hline Travel & 29 & 7.85 (5.23-13.81) & 32 & 22.17 (6.54-38.17) & 24 & 11.92 (7.12-25.88) & 17 & $15.27(7.63-27.63)$ \\
\hline Food & 8 & $3.70(1.63-8.00)$ & 24 & 9.20 (4.18-16.34) & 21 & 9.45 (4.73-13.09) & 8 & $3.31(1.93-4.91)$ \\
\hline Subtotal cost per person & 31 & $11.63(7.20-16.21)$ & 32 & 39.58 (13.74-67.28) & 26 & 26.79 (14.83-47.11) & 17 & $55.25(25.08-145.76)$ \\
\hline Hospitalization & 2 & $47.27(36.35-58.16)$ & 3 & 72.70 (36.35-290.80) & 4 & 399.85 (254.45-2399.13) & 1 & - \\
\hline $\begin{array}{l}\text { Total cost per person } \\
\quad \text { (including hospitalization) }\end{array}$ & 31 & $11.63(7.85-16.72)$ & 32 & 41.62 (13.74-69.36) & 26 & 30.97 (19.63-68.74) & 17 & $81.13(31.62-145.76)$ \\
\hline
\end{tabular}


TABLE 5

Personal income loss (A), total costs (B), borrowed money (C), and catastrophic costs at $20 \%$ threshold of household income (D) of patients who were recruited at 6 months $(n=106)$ according to the site of recruitment

\begin{tabular}{|c|c|c|c|c|c|c|c|c|}
\hline & \multicolumn{2}{|r|}{ Community health center } & \multicolumn{2}{|r|}{ Public hospital } & \multicolumn{2}{|r|}{ Private hospital } & \multicolumn{2}{|r|}{ Private practice } \\
\hline & $N$ & Median (IQR) USD & $N$ & Median (IQR) USD & $N$ & Median (IQR) USD & $N$ & Median (IQR) USD \\
\hline $\begin{array}{l}\text { A. Personal income } \\
\text { loss resulting } \\
\text { from TB }(n=57)^{\star}\end{array}$ & 16 & 156.31 (108.83-708.83) & 18 & $257.36(61.80-727.00)$ & 14 & $191.20(54.53-508.91)$ & 9 & 101.78 (70.28-763.36) \\
\hline $\begin{array}{l}\text { B. Total costs } \\
(n=106) \dagger\end{array}$ & 31 & 147.36 (103.53-438.17) & 32 & 243.66 (133.91-627.34) & 26 & 334.89 (179.79-550.9) & 17 & $285.28(204.94-438.87)$ \\
\hline $\begin{array}{l}\text { C. Borrowed } \\
\text { money }(n=106)\end{array}$ & 11 & 36.35 (7.27-72.70) & 10 & 109.05 (21.81-218.10) & 7 & $145.40(14.54-363.50)$ & 5 & $145.41(72.70-218.10)$ \\
\hline $\begin{array}{l}\text { D. Catastrophic } \\
\text { costs }(n=83) \ddagger\end{array}$ & $\begin{array}{c}N \\
6 / 25\end{array}$ & $\begin{array}{c}\%(95 \% \mathrm{Cl}) \\
24.0(6.0-42.0)\end{array}$ & $\begin{array}{c}N \\
6 / 25\end{array}$ & $\begin{array}{c}\%(95 \% \mathrm{Cl}) \\
24.0(6.0-42.0)\end{array}$ & $\underset{5 / 20}{N}$ & $\begin{array}{c}\%(95 \% \mathrm{Cl}) \\
25.0(4.2-45.8)\end{array}$ & $\begin{array}{c}N \\
5 / 13\end{array}$ & $\begin{array}{c}\%(95 \% \mathrm{Cl}) \\
38.5(7.9-69.1)\end{array}$ \\
\hline
\end{tabular}

direct costs for TB patients in a systematic review. ${ }^{3}$ After removal of hospitalization costs, key cost categories included diagnostic tests such as sputum microscopy and chest X-ray, non-TB-related medications, and travel costs for people recruited in public hospitals. Although the median cost for each of these categories was relatively small, the cumulative effect leading up to diagnosis could impact on patients not seeking treatment, not having the necessary tests, or having to seek alternative ways of covering the costs. This is of particular importance given that $33 \%$ of patients in our study were from income-poor households, which is considerably higher than the $5.7 \%$ in the general population of Indonesia in 2017. ${ }^{21}$ Pretreatment direct costs in our study were higher than those in several countries (Cambodia $\$ 14.80,{ }^{22}$ Ghana $\$ 14,{ }^{4}$ Vietnam $\$ 8,{ }^{4}$ the Dominican Republic $\$ 8,{ }^{4}$ and other parts of Indonesia $\$ 11^{17}$ ) but lower than that reported in a systematic review of TB patients in low- and middle-income countries $(\$ 136.20) .^{3}$ The latter, however, included direct costs across the whole time before and after diagnosis; even if $50 \%$ of these costs were before diagnosis, the estimate is still higher than that found in our study.

Our analysis also showed that the median pretreatment cost was higher for patients who visited a PP or informal healthcare provider when they first became unwell, despite having a good network of publicly funded $\mathrm{CHCs}$ throughout the city. Estimates have shown that approximately $50 \%$ of people in Indonesia access such a provider when they first become unwell, ${ }^{9}$ the reasons for which are many and complex. $^{7}$ The NTP recognizes that PPs need to be included in the TB control program for improved diagnosis, treatment, and notification of TB. This would likely reduce the costs incurred by patients as well as impacting on the overall incidence and prevalence of TB in the community. Last, and not surprisingly, the median pretreatment cost was higher for people who had no insurance. The National Health Insurance scheme was started in January 2014 and in just over 5 years, $74 \%$ of Indonesia's population are under the program, ${ }^{12}$ slightly higher than those among our study participants $(69 \%)$. Those who remain uninsured are thought to be employed in the informal workforce and are likely to be particularly vulnerable should they become unwell. It is essential that the national health insurance program reach these people.
Using data from the subsample $(n=106)$ of the participants, we were able to show post-diagnosis direct costs, and total cost (direct and indirect costs) from onset of symptoms through to the end of 6 months of treatment. Similar to that reported for pretreatment costs, a large post-diagnosis direct cost was related to hospitalization. Patients recruited in PPs had the highest median cost $(\$ 55.25)$, mostly related to medication, administration, and diagnostic tests. Travel costs appeared to be high in patients recruited in public hospitals (\$22.17), which is likely due to the distance to access treatment. Ensuring patients are referred back to their local $\mathrm{CHC}$ for treatment, as recommended by the NTP, would reduce this cost.

The median total cost (\$243.66) was less than that reported in a systematic review (\$397), ${ }^{3}$ and in Cambodia (\$290), ${ }^{22}$ Vietnam (\$758), and the Dominican Republic $(\$ 742)^{4}$ but more than that in Ethiopia $(\$ 177)^{23}$ and one study in Ghana (\$202). ${ }^{4}$ A separate nationally representative survey in Ghana, however, reported total costs of $\$ 429 .{ }^{24}$ Another study undertaken in Indonesia reported the total median cost was $\$ 133 .^{17}$ However, participants were recruited only from public health facilities. Almost a third of the subsample of patients reported having to borrow money and $12 \%$ sold assets to cover costs, which is similar to that reported in other countries $3,4,22,24,25$ and in other parts of Indonesia. ${ }^{17}$ Furthermore, $26 \%$ of patients had costs that could be described as catastrophic. With just over two-thirds of the total cost (69\%) related to income loss, ways to prevent this need to be embedded in the wider social sector. The catastrophic cost estimate, however, needs to be considered with caution, given the small sample of 83 people who were recruited at the 6-month treatment review period who had available household income information. Fuady and others ${ }^{25}$ ran various hypothetical scenarios to estimate the effect on TB-affected households in Indonesia and reported that to effectively reduce the proportion of households with catastrophic costs, innovative social protection policies are required. Whether this is delivered in the form of cash transfers, as has been trialed in Peru, ${ }^{26}$ or in food or transport supplements, or income protection, ${ }^{25}$ options need to be considered in the local context of what is feasible and deliverable.

Limitations of our study are, first, all cost data are selfreported and patients were recruited at different times in their 
TB illness trajectory. We were able to show that participants recruited at the time of diagnosis reported higher median pretreatment direct costs than those recruited at 2 and 6 months, indicating that there may have been some recall bias and that the pretreatment median direct cost estimate is likely to be an underestimate. Second, although the $\mathrm{CHC}$ areas were randomly selected, the selection of public and private hospitals and PPs were those within these areas who agreed to recruit patients for the study and, therefore, may not be representative of TB patients in Bandung. However, as opposed to many other studies, having patients in our study recruited from both the public and private sectors provides a more realistic portrayal of out-of-pocket costs. Last, the small number of participants recruited at the time of their 6-month treatment review limited the ability to investigate factors associated with direct costs as well as the reliable interpretation of catastrophic costs, as already mentioned.

Results from our study in Bandung, Indonesia, show that patients face not inconsequential costs before their TB diagnosis, despite much of TB care being free of charge. Early diagnosis of patients and streamlining of diagnostic services would help alleviate this cost burden. Moreover, to reach the WHO target of having no TB-affected family facing catastrophic costs will require substantial input, across a range of activities and policies from the NTP and other related governmental sectors.

Received November 11, 2019. Accepted for publication May 27, 2020.

Published online July 6, 2020.

Acknowledgments: We would like to thank the Bandung City Health Office, staff in the public and private hospitals, and PPs for their support during data collection of this study, and the patients who agreed to participate.

Financial support: The study was funded by the University of Otago, Dunedin School of Medicine Dean's Bequest Grant and a Partnership for Enhanced Engagement in Research (PEER) grant under Prime Agreement Number AID-OAA-A-11-00012 by the National Academy of Sciences (NAS) and the U.S. Agency for International Development (USAID).

Authors' addresses: Susan M. McAllister and Trudy Sullivan, Department of Preventive and Social Medicine, University of Otago, Dunedin, New Zealand, E-mails: sue.mcallister@otago.ac.nz and trudy.sullivan@otago.ac.nz. Bony Wiem Lestari and Panji Fortuna, Department of Public Health, Faculty of Medicine, Universitas Padjadjaran, Bandung, Indonesia, E-mails: bony.wiem@gmail.com and hadisoemartopanji@gmail.com. Nur Afifah, Tuberculosis Working Group, Infectious Disease Research Center, Faculty of Medicine, Universitas Padjadjaran, Bandung, Indonesia, E-mail: nurafifah3393@ gmail.com. Rosye Arosdiani Apip, Division of Disease Control and Prevention, Bandung Municipal Health Office, Bandung, Indonesia, E-mail: rosyehadiana@gmail.com. Megan Murray, Department of Global Health and Social Medicine, Harvard Medical School, Boston, MA, E-mail: megan.murray.epi@gmail.com. Philip C. Hill, Department of Preventive and Social Medicine, School of Medicine, University of Otago, Dunedin, New Zealand, E-mail: philip.hill@otago.ac.nz. Bachti Alisjahbana, Faculty of Medicine, Universitas Padjadjaran, Bandung, Indonesia, E-mail: b.alisjahbana@gmail.com.

\section{REFERENCES}

1. Hargreaves JR, Boccia D, Evans CA, Adato M, Petticrew M, Porter JD, 2011. The social determinants of tuberculosis: from evidence to action. Am J Public Health 101: 654-662.

2. Lönnroth K, Aung T, Maung W, Kluge H, Uplekar M, 2007. Social franchising of TB care through private GPs in Myanmar: an assessment of treatment results, access, equity and financial protection. Health Policy Plan 22: 156-166.

3. Tanimura T, Jaramillo E, Weil D, Raviglione M, Lönnroth K, 2014. Financial burden for tuberculosis patients in low-and middleincome countries: a systematic review. Europ Resp J 43: 1763-1775.

4. Mauch V, Bonsu F, Gyapong M, Awini E, Suarez P, Marcelino B, Melgen RE, Lönnroth K, Nhung NV, Hoa NB, 2013. Free tuberculosis diagnosis and treatment are not enough: patient cost evidence from three continents. Int J Tuberc Lung Dis 17: 381-387.

5. World Health Organization, 2015. The End TB Strategy. Geneva, Switzerland: WHO. Available at: http://www.who.int/tb/strategy/ en/. Accessed April 25, 2018.

6. World Health Organization, 2019. Global Tuberculosis Report. Geneva, Switzerland: WHO.

7. Uplekar M, Pathania V, Raviglione M, 2001. Private practitioners and public health: weak links in tuberculosis control. Lancet 358: 912-916.

8. Satyanarayana S, Nair SA, Chadha SS, Shivashankar R, Sharma G, Yadav S, Mohanty S, Kamineni V, Wilson NC, Harries AD, 2011. From where are tuberculosis patients accessing treatment in India? Results from a cross-sectional community based survey of 30 districts. PLoS One 6: e24160.

9. Mahendradhata Y, Lestari T, Probandari A, Indriarini LE, Burhan E, Mustikawati D, Utarini A, 2015. How do private general practitioners manage tuberculosis cases? A survey in eight cities in Indonesia. BMC Res Notes 8: 564

10. Mboi N, 2015. Indonesia: on the way to universal health care. Health Syst Reform 1: 91-97.

11. Mahendradhata $Y$, Trisnantoro L, Listyadewi S, Soewondo P, Marthias T, Harimurti P, Prawira J, 2017. The Republic of Indonesia Health System Review. Health Systems in Transition. New Delhi, India: WHO, Regional Office for South-East Asia.

12. Health Policy Plus, 2018. Indonesia Makes Inroads towards Universal Health Coverage through National Health Insurance Program, Paving the Way for Others. Available at: http:// www.healthpolicyplus.com/indonesiaUHC.cfm. Accessed September 17, 2019.

13. KNCV Tuberculosis Foundation, World Health Organization, and Japan Anti-Tuberculosis Association, 2008. The Tool to Estimate Patients' Costs. The Hague, The Netherlands: TBCTA.

14. World Health Organization, 2015. Protocol for Survey to Determine Direct and Indirect Costs Due to TB and to Estimate Proportion of TB-Affected Households Experiencing Catastrophic Total Costs Due to TB. Geneva, Switzerland: WHO.

15. Pedrazzoli D, Borghi J, Viney K, Houben RMGJ, Lönnroth K, 2019. Measuring the economic burden for TB patients in the end TB Strategy and universal health coverage frameworks. Int $J$ Tuberc Lung Dis 23: 5-11.

16. Nhung NV, Hoa NB, Anh NT, Anh LTN, Siroka A, Lonnroth K, Garcia Baena I, 2018. Measuring catastrophic costs due to tuberculosis in Viet Nam. Int J Tuberc Lung Dis 22: 983-990.

17. Fuady A, Houweling TAJ, Mansyur M, Richardus JH, 2018. Catastrophic total costs in tuberculosis-affected households and their determinants since Indonesia's implementation of universal health coverage. Infect Dis Poverty 7: 3.

18. Harris PA, Taylor R, Thielke R, Payne J, Gonzalez N, Conde JG, 2009. Research electronic data capture (REDCap)-a metadata-driven methodology and workflow process for providing translational research informatics support. J Biomed Inform 42: 377-381.

19. The World Bank, 2019. Official Exchange Rate. Available at: https:// data.worldbank.org/indicator/PA.NUS.FCRF. Accessed August 12, 2019.

20. StataCorp, 2013. Stata Statistical Software: Release 12.1. College Station, TX: StataCorp.

21. World Bank, 2017. Poverty \& Equity. Available at: http:// povertydata.worldbank.org/poverty/country/IDN. Accessed September 3, 2019.

22. Morishita F, Yadav RP, Eang MT, Saint S, Nishikiori N, 2016. Mitigating financial burden of tuberculosis through active case finding targeting household and neighbourhood contacts in Cambodia. PLoS One 11: e0162796.

23. Getahun B, Wubie M, Dejenu G, Manyazewal T, 2016. Tuberculosis care strategies and their economic consequences for 
patients: the missing link to end tuberculosis. Infect Dis Poverty 5: 93.

24. Pedrazzoli D, Siroka A, Boccia D, Bonsu F, Nartey K, Houben R, Borghi J, 2018. How affordable is TB care? Findings from a nationwide TB patient cost survey in Ghana. Trop Med Int Health 23: 870-878.

25. Fuady A, Houweling TAJ, Mansyur M, Burhan E, Richardus JH, 2019. Effect of financial support on reducing the incidence of catastrophic costs among tuberculosis-affected households in Indonesia: eight simulated scenarios. Infect Dis Poverty 8: 10.

26. Wingfield T, Boccia D, Tovar MA, Huff D, Montoya R, Lewis $\mathrm{JJ}$, Gilman RH, Evans CA, 2015. Designing and implementing a socioeconomic intervention to enhance TB control: operational evidence from the CRESIPT project in Peru. BMC Pub Health 15: 810. 